Institute of $\mathbf{F}_{\text {ood and }} \mathbf{A g r i c u l t u r a l}_{\mathbf{S}} \mathbf{S}_{\text {ciences }}$

\title{
Como Realizar un Plan de Gastos - Primer Paso: ¿Cuáles son sus Metas? ${ }^{1}$
}

Nayda I Torres ${ }^{2}$

Todos necesitamos aprender a manejar nuestro dinero. Aquí les presentamos un ejercicio de siete pasos para ayudarles a manejar su dinero. Miles de ciudadanos de la Florida han usado ejercicios como este para aprender a organizar sus archivos financieros y hacer presupuestos. Muchas personas han utilizado este ejercicio para reducir sus deudas y ahorrar bastante dinero para hacer o comprar lo que ellos han querido.

¿Qué quiere hacer? ¿Está buscando usted maneras de ahorrar dinero para pagar sus facturas y sus deudas o llegar desahogadamente al final del mes?

¿Necesita usted ir al dentista, comprar o arreglar cosas para su casa y su familia, pagar para el cuidado de sus hijos, o prepararse para poder encontrar un trabajo mejor? ¿Quiere usted comprar una bicicleta para sus hijos y/o enviarlos a la universidad?

Enumere tres cosas que usted quiere hacer o comprar en el futuro. Éstas son sus metas a largo plazo. ¿Qué necesita usted o quiere hacer ahora mismo? Éstas son sus metas a corto plazo.

\begin{tabular}{||c||c||}
\hline \multicolumn{1}{|c||}{ Futuro } & Ahora \\
\hline & \\
\hline & \\
\hline & \\
\hline
\end{tabular}

1. Este documento es la Hojuela FCS7167-Span, una serie del Departamento de Ciencias de la Familia, Juventud y Comunidad, Servicio de Extensión Cooperativa de Florida, Instituto de Alimentos y Ciencias Agrícolas, Universidad de Florida. Fecha de publicación: Octubre 2002. Por favor visite el web de EDIS http://edis.ifas.ufl.edu

2. Escrito por Nayda I. Torres, Profesora, Familia y Economía del Consumidor y la versión en Inglés ha sido revisada por Josephine Turner, CFP, Profesora, Familia y Economía del Consumidor, Servicio de Extensión Cooperativa, Departamento de Ciencias de la Familia, Juventud y Comunidad, Instituto de Alimentos y Ciencias Agrícolas, University of Florida, Gainesville, 32611. Traducido por: Sergio Romero.

El Instituto de Alimentos y Ciencias Agrícolas es un patrono que ofrece igualdad de oportunidad de empleo, autorizado a proveer investigación, información educativa y otros servicios a individuos y a instituciones que ejerzan sus funciones sin tomar en consideración raza, color, sexo, edad, incapacidad o nacionalidad. Para información sobre como obtener otras publicaciones del Servicio de Extensión, comuníquese con la Oficina del Servicio de Extensión Cooperativa de su Condado. Servicio de Extensión Cooperativa de Florida / Instituto de Alimentos y Ciencias Agrícolas / Universidad de Florida, Christine Taylor Waddill, Decano 
Si usted sabe exactamente como obtiene su dinero, cómo lo gasta, y el costo de las cosas que necesita o quiere, puede manejar su dinero de manera que le ayude a alcanzar sus metas a corto y largo plazo.

Use las tablas que incluimos para intentar alcanzar sus metas. Enumere las tres cosas más importantes que usted quiere lograr en los próximos 12 meses en la tabla de metas a corto plazo. Después, enumere tres metas que usted desee lograr en el futuro en la tabla de metas a largo plazo.

Averigüe cuánto le costará alcanzar cada meta. Sume las cantidades.

Concéntrese en alcanzar sus metas a corto plazo, pero siempre tenga presente sus metas a largo plazo. Prepare sus metas a corto plazo para que éstas le ayuden a lograr sus metas a largo plazo. Comience a ahorrar ahora mismo y de manera regular para poder alcanzar sus metas.

Si usted es como la mayoría de los americanos, su primera prioridad probablemente sea la de atender sus necesidades inmediatas y pagar sus facturas mensuales.

Contacte con un consejero financiero en una organización de servicios comunitarios o con un/a especialista en Ciencias de la Familia y el Consumidor del Servicios de Extensión Cooperativa de la Universidad de Florida para obtener más información.

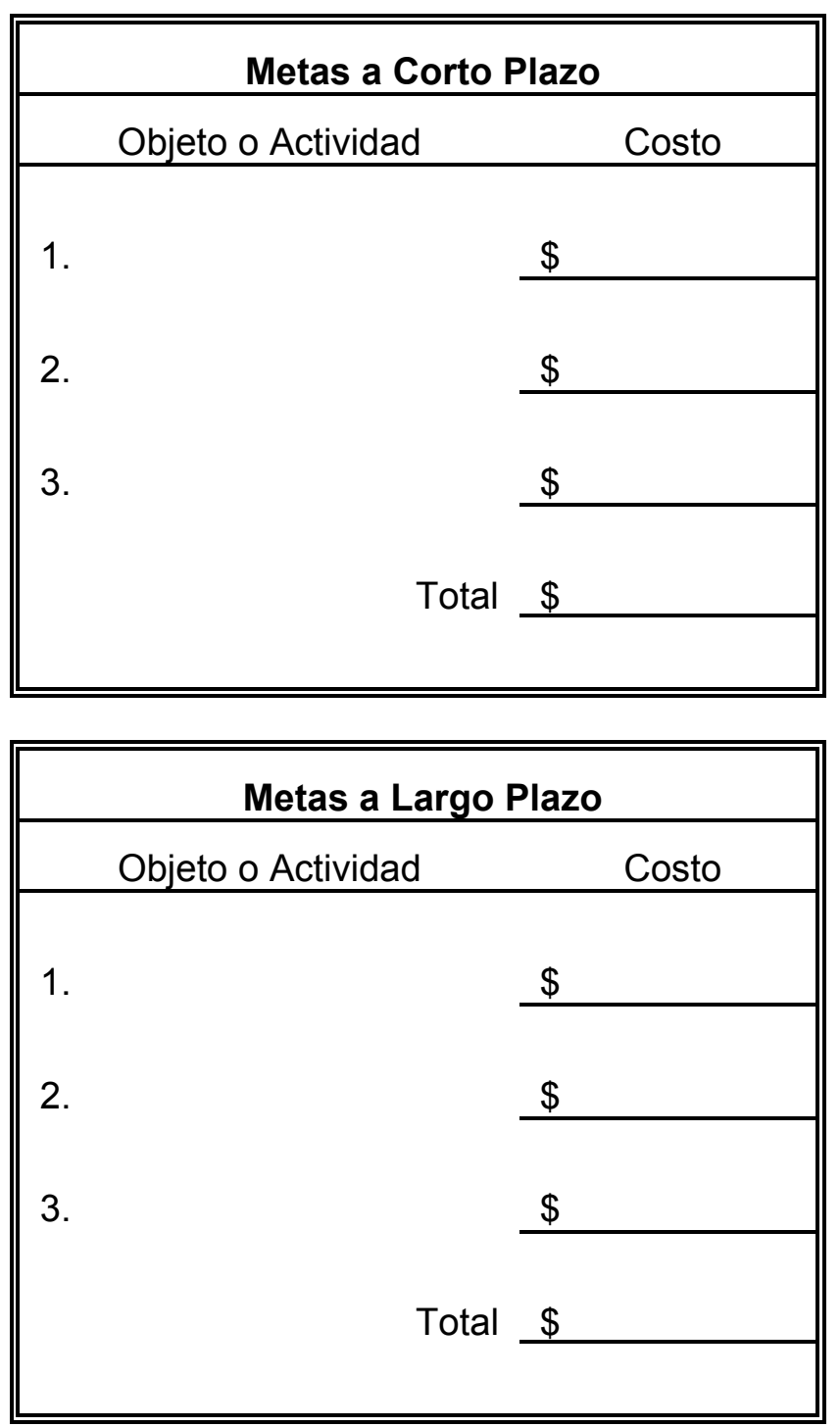

